\title{
Save Energy Now in Your Process Heating Systems
}

\section{Facts \& Figures}

- Nearly one-third of the nation's total energy use is consumed in U.S. industrial facilities.

- Industry consumes more than $40 \%$ of the nation's total use of natural gas.

- Even plants with energy management programs can often save $10 \%$ to $15 \%$ more using best practices to increase energy efficiency.

- Process heating energy use and costs can often be reduced $5 \%$ to $15 \%$ through best practices and system improvements.

\section{Benefits}

- Energy efficiency improvements can reduce utility bills and improve your plant's bottom line.

- Many improvements require little or no extra investment, are easy to implement, and have payback times of less than a year.

- Strategies that increase energy efficiency often reduce operating and maintenance costs, minimize waste, and enhance production.

- Energy efficiency helps to reduce negative impacts on the environment and can enhance corporate community relations programs.

\section{Resources}

For more information on process heating efficiency, to obtain DOE's Process Heating Assessment and Survey Tool (PHAST), and to learn more about DOE Qualified Specialists and training opportunities, visit the BestPractices Web site, www.eere.energy.gov/industry/ bestpractices/.
Process heating accounts for about $36 \%$ of the total energy used in industrial manufacturing applications. And in some industries, this percentage is much higher. In the glass industry, for example, process heating accounts for about $80 \%$ of energy consumption, according to the U.S. Department of Energy's (DOE) Manufacturing Energy Consumption Survey.

As energy costs continue to rise, industrial plants need effective ways to reduce the energy used for process heating. To help meet this need, the DOE Industrial Technologies Program (ITP) works with the nation's most energy-intensive plants to uncover opportunities for reducing energy use and costs while maintaining - or increasing - productivity.

Process heating systems include combustion systems that run on fossil fuels and biomass; electric systems; and heat recovery and exchange systems (see diagram). Process heating systems can also include sensors, controls, material handling equipment, emission controls, and safety equipment. About $90 \%$ of process heating energy comes from the combustion of fossil fuels; electricity supplies the rest. Advanced processes, improved designs, and thermal efficiency gains are helping to reduce the environmental impacts of combustion-related emissions.

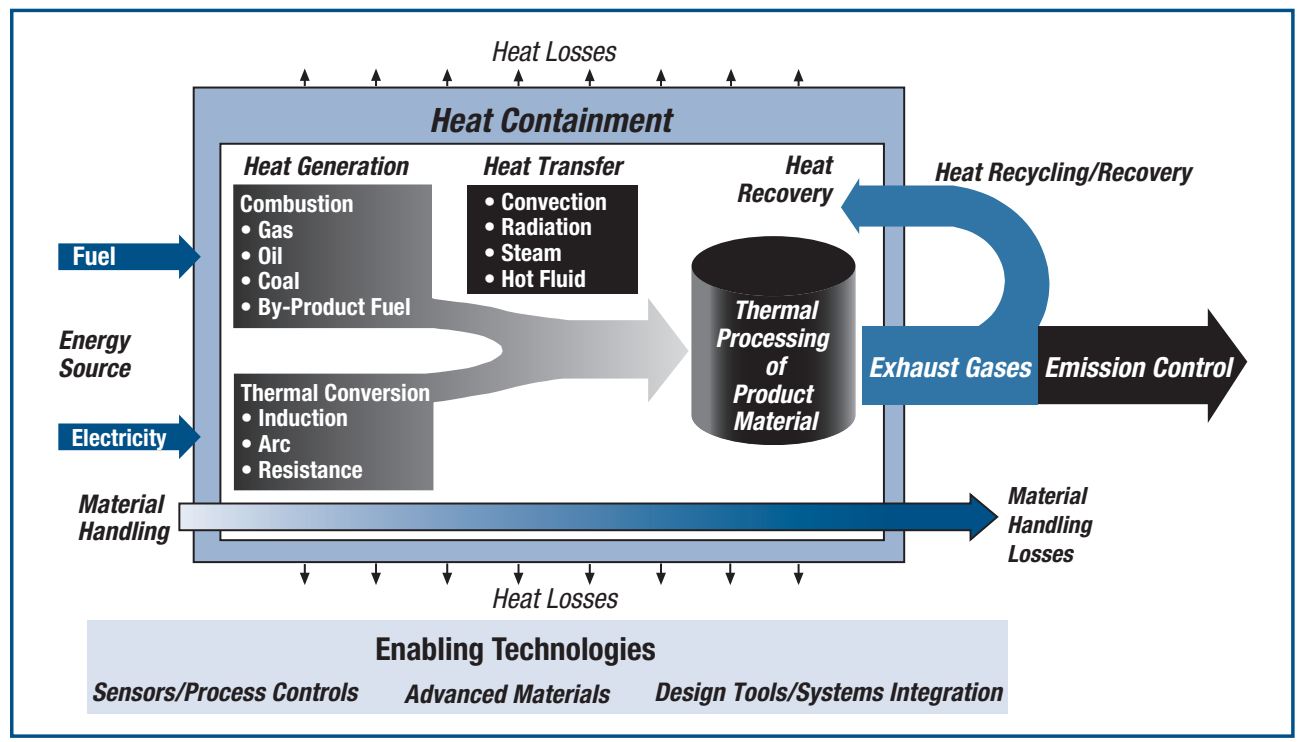

Key Components of a Process Heating System (Source: Improving Process Heating Performance: A Sourcebook for Industry, available online at www.eere.energy.gov/ indusry/bestpractices/) 


\section{Potential for Savings}

Anywhere from $15 \%$ to $85 \%$ of the energy supplied to industrial process heating equipment is actually used for heating; the rest is often lost-for example, to exhaust streams such as flue gases. However, today's heat recovery technologies allow at least part of this energy to be reused. Along with making sure that burners and other combustion equipment are operating at peak efficiency, reducing heat losses and finding good ways to recover and reuse waste heat could be the most beneficial improvements you can make.

Improving the operation of your plant's process heating systems can yield significant savings. Often, the best opportunities for savings are found among higher temperature processes. But savings can be found in all temperature ranges throughout your plant. Using DOE's decision tools software, such as the Process Heating Assessment and Survey Tool (PHAST), and efficient system management practices, plants can often reduce the amount of energy consumed in their process heating operations from $5 \%$ to $15 \%$. Some efficiency measures, such as preheating combustion air, have reduced process heating-related plant energy use and costs as much as $30 \%$.

\section{Start Saving Today}

Some typical opportunities for increasing the efficiency of process heating systems are shown in the table. Using ITP's resources - such as tip sheets, sourcebooks, case studies, and software assessment tools - you can begin assessing and improving your process heating systems today.

\section{Typical Ways to Increase the Energy Efficiency of Process Heating Systems* Heat Generation \\ - Control the air-to-fuel ratio \\ - Preheat combustion air \\ - Use oxygen-enriched combustion air}

\section{Heat Transfer}

- Improve heat transfer with advanced burners and controls

- Improve heat transfer in the furnace

\section{Heat Recovery}

- Preheat fluid or load

- Use heat cascading

- Use fluid heating or waste heat recovery boilers

- Use absorption cooling

- Use organic Rankine cycles to produce electricity

\section{Supporting Technologies}

- Install high-turndown combustion systems

- Use programmed heating temperature setting for part-load operation

- Monitor and control exhaust gas oxygen, unburned hydrocarbons, and carbon monoxide

- Use furnace pressure controls

- Locate sensors correctly

*For more, look for Improving Process Heating Performance: A Sourcebook for Industry and process heating tip sheets in the Resources section of the BestPractices home page: www.eere.energy.gov/industry/bestpractices.

ITP provides U.S. industries with software assessment tools, training, technical information, and assistance. These resources and energy management practices help plants improve the energy efficiency of their process heating, steam, pumps, compressed air, and other systems; reduce operating costs; and improve their bottom line.
BestPractices is part of the Industrial

Technologies Program, and supports

DOE's strategy to help the country's

most energy-intensive industries

improve their competitiveness.

BestPractices brings together emerging

technologies and energy-management

best practices to help companies

begin improving energy efficiency,

environmental performance,

and productivity right now.

BestPractices emphasizes plant

systems, where significant efficiency

improvements and savings can be

achieved. Industry gains easy access

to near-term and long-term solutions

for improving the performance of

process heating, steam, pumps,

compressed air and other motor-

driven systems. In addition, the

Industrial Assessment Centers provide

comprehensive industrial energy

evaluations to small- and medium-size

manufacturers.

\section{A Strong Energy Portfolio}

\section{for a Strong America}

Energy efficiency and clean,

renewable energy will mean a stronger

economy, a cleaner environment,

and greater energy independence

for America. Working with a wide

array of state, community, industry,

and university partners, the U.S.

Department of Energy's Office of

Energy Efficiency and Renewable

Energy invests in a diverse portfolio of

energy technologies.

For More Information, Contact:

EERE Information Center

1-877-EERE-INF

(1-877-337-3463)

www.eere.energy.gov

Or visit these Web sites:

Industrial Technologies Program (ITP)

www.eere.energy.gov/industry

ITP BestPractices

www.eere.energy.gov/industry/

bestpractices

Save Energy Now

www.eere.energy.gov/industry/

saveenergynow

U.S. Department of Energy

Energy Efficiency and Renewable Energy

Washington, DC 20585-0121

DOE/G0-102006-2274

January 2006 